Original Article

\title{
FABRICATION OF DRUG DELIVERY SYSTEM FOR CONTROLLED RELEASE OF CURCUMIN, INTERCALATED WITH MAGNETITE NANOPARTICLES THROUGH SODIUM ALGINATE/POLYVINYLPYRROLIDONE-CO-VINYL ACETATE SEMI IPN MICROBEADS
}

\section{T. JITHENDRA ${ }^{1}$, O. SREEKANTH REDDY ${ }^{1}$, M. C. S. SUBHA ${ }^{1 *}$, K. CHOWDOJI RAO ${ }^{2}$}

${ }^{1}$ Department of Chemistry, Sri Krishnadevaraya University, Ananthapuramu 515003, India, ${ }^{2}$ Department of Polymer Science and Technology, Sri Krishnadevaraya University, Ananthapuramu 515003, India

Email: mcssubha3@gmail.com

Received: 05 Apr 2020, Revised and Accepted: 13 Jul 2020

\begin{abstract}
Objective: The aim of the present work is to fabricate curcumin (CUR) encapsulated microbeads in the polymer matrix of sodium alginate (SA)/poly(vinylpyrrolidone)-co-vinyl acetate (PVP-co-VAc) intercalated with magnetite nanoparticles (MNPs) using glutaraldehyde (GA)/calcium chloride $\mathrm{CaCl}_{2}$ as the crosslinker.

Methods: Magnetite nanoparticles (MNPs) were synthesized by a modified co-precipitation method. Curcumin encapsulated SA/PVP-co-VAc microbeads, intercalated with MNPs were prepared by simple ionotropic gelation technique. The formation of microbeads and uniform distribution of curcumin were characterized using spectroscopic methods. In addition, swelling and drug release kinetic studies of the microbeads were performed in simulated intestinal fluid $\left(\mathrm{pH} \mathrm{7.4)}\right.$ and simulated gastric fluid $(\mathrm{pH} 1.2)$ at $37^{\circ} \mathrm{C}$.

Results: Microbeads formation was confirmed by Fourier Transform Infrared (FTIR). Differential Scanning Calorimetry (DSC) studies reveal that the peak at $181^{\circ} \mathrm{C}$ of CUR was not observed in CUR loaded microbeads, which confirms that CUR was encapsulated at the molecular level in the polymer matrix. The X-Ray diffraction (X-RD) diffractograms of CUR shows $2 \theta$ peaks between $12-28^{\circ}$, which indicated the crystalline nature of CUR, these peaks are not found in CUR loaded microbeads, suggesting that the drug has been molecularly dispersed in the polymer matrix. The X-RD $2 \theta$ peaks of MNPs are observed in the MNPs loaded microbeads, which confirms that MNPs are successfully loaded in the microbeads. The swelling studies and in vitro release studies were performed at $\mathrm{pH} 1.2$ and 7.4. The results reveal that at pH 7.4 highest swelling and release was observed which confirms that the developed microbeads are $\mathrm{pH}$ sensitive and are suitable for intestinal drug delivery. The drug release kinetics fit into the Korsmeyer-Peppas equation, indicating non-Fickian diffusion.
\end{abstract}

Conclusion: The results concluded that the present system as dependent on $\mathrm{pH}$ of the test medium and hence suggest suitability for intestinal drug delivery.

Keywords: Sodium alginate, Poly(vinylpyrrolidone)-co-vinyl acetate, Magnetite nanoparticles, Curcumin, Microbeads

C 2020 The Authors. Published by Innovare Academic Sciences Pvt Ltd. This is an open access article under the CC BY license (http://creativecommons.org/licenses/by/4.0/) DOI: http://dx.doi.org/10.22159/ijap.2020v12i5.37761. Journal homepage: https://innovareacademics.in/journals/index.php/ijap

\section{INTRODUCTION}

The best acceptable route for drug administration is an oral route, due to ease of administration and gastrointestinal physiology provides additional flexibility in the design of dosage form compared to other routes [1]. Normally, conventional oral drug administration does not provide a controlled release or target specificity [2]. Further, it has several drawbacks such as poor patient compliance, frequent dosing poor bioavailability etc. To overcome these problems novel drug delivery systems (NDDS) such as controlled/sustained drug release systems with IPNs(Interpenetrating polymer networks) have been evolved $[3,6]$. Polymers play a vital role in the development of controlled drug delivery systems because of their favourable and flexible features such as biocompatibility, non-toxic, biodegradability and also it can be easily produced at industrial scale [4].

Sodium alginate (SA) is anionic polysaccharide, composed of two different kinds of hexuronic acid residues such as $\beta$-D-mannuronic acid (M) and $\alpha$-L-guluronic acid (G) arranged as random or in an alternating manner $[5,7]$. It has several biomedical and biotechnological applications due to its specific properties such as hydrophilicity, biodegradability, biocompatibility and non-toxicity [8-10]

Poly(vinylpyrrolidone)-co-vinyl acetate (PVP-co-VAc) is a water soluble block copolymer consisting of both hydrophobic and hydrophilic components in its structure, which facilitates the increased solubilisation of drugs [11]. The presence of hydrophobic part in PVP-co-VAc, acts as a good drug carrier for hydrophobic or less water-soluble drugs. The applications of PVP-co-VAc in biomedical applications are scanty. Previously Bailly et al., [12] reported that Poly(N Vinylpyrrolidone)-block-poly(vinyl acetate) (PVP-b-PVAc) is a good interesting candidate for the delivery of hydrophobic drug (clofazimine).
Curcumin (CUR), a polyphenol of turmeric (diferuloylmethane), a natural bioactive compound, is obtained from Curcuma longa [13]. It has anti-inflammatory, anti-oxidant, antimicrobial, antispasmodic and antiproliferative activity against different cancer cells [14-16]. However, its biomedical applications are very scanty due to low aqueous solubility, limited bioavailability and potentially lipophilic characteristics [17], which have limited in vivo efficacy of curcumin [18]. To overcome this problem, various types of micro and nanocarriers have been proposed, such as micelles, nanoparticles, and iron oxide particles [19]

Magnetite nanoparticles (MNPs) are increasingly being considered for a number of biomedical applications due to their inherent superparamagnetic properties, ultra-fine size and biocompatibility [20-22]. The functional properties of the MNPs can be tailored for specific biological functions, such as drug delivery [23], hyperthermia or magnetic targeting [24-26], magnetic resonance imaging (MRI) [2729]. Among the MNPs, iron oxide nanoparticles (magnetite $\Upsilon-\mathrm{Fe}_{2} \mathrm{O}_{3}$ or magnetite $\mathrm{Fe}_{3} \mathrm{O}_{4}$ ) are the most popular formulations. The large surface to volume ratio of MNPs renders relative high loading in biocompatible materials [28]. Owing to nanosize, MNPs can accumulate in tumor cells by the enhanced permeability and retention (EPR) effect [30]. Further malignant tumors have high heat sensitivity than normal tissues in the temperature range of $41-47{ }^{\circ} \mathrm{C}$ and the property is exploited for chemotherapeutic applications [31]. MNP drug delivery systems have incorporated small traditional molecules like paclitaxel, doxorubicin and methotrexate [22]. Natural macromolecules like curcumin have not been researched earlier with MNP combination for cancer therapy.

In the current work, SA/PVP-co-VAc microbeads were prepared by a simple gelation technique. The microbeads were characterized using fourier transform infrared spectroscopy, differential scanning 
calorimetry, X-ray diffraction and scanning electron microscopy. In addition, swelling studies and drug release kinetics of the microbeads have been reported. The main objective of the present work is to encapsulate the curcumin molecules intercalated with magnetite nanoparticles into SA/PVP-co-VAc microbeads and to study the effect of MNPs on controlled drug delivery of curcumin for novel chemotherapeutic applications.

\section{MATERIALS AND METHODS}

\section{Materials}

Poly (vinylpyrrolidone)-co-vinylacetate, ferrous chloride $\left(\mathrm{FeCl}_{2} .4 \mathrm{H}_{2} \mathrm{O}\right)$, and tetramethylammonium hydroxide were purchased from Sigma-Aldrich (USA). Sodium alginate, glutaraldehyde (GA) ferric chloride $\left(\mathrm{FeCl}_{3} \cdot 6 \mathrm{H}_{2} \mathrm{O}\right)$, and calcium chloride were purchased from Sd. Fine chemicals, Mumbai, India. Curcumin was purchased from Loba Chemicals, Mumbai, India. Water used was of high purity grade after double distillation.

\section{Methods}

\section{Synthesis of magnetite nanoparticles (MNPs)}

Magnetite nanoparticles (MNPs) were synthesized by modified coprecipitation method [32] using ferrous and ferric salts. $5.2 \mathrm{~g}$ of $\mathrm{FeCl}_{3 .} 6 \mathrm{H}_{2} \mathrm{O}$ and $2.0 \mathrm{~g}$ of $\mathrm{FeCl}_{2} .4 \mathrm{H}_{2} \mathrm{O}$ were weighed and transferred into $250 \mathrm{ml}$ round bottom flask and $100 \mathrm{ml}$ of deoxygenated distilled water was added and stirred at $300 \mathrm{rpm}$ for $2 \mathrm{~h}$ under nitrogen atmosphere. Then ammonium hydroxide solution was added slowly to the reaction mixture to raise the $\mathrm{pH}$ to 8.0. Then the solution turned from brown to black colour, which indicates the formation of magnetite nanoparticles. The magnetite nanoparticles formed were separated and washed with distilled water followed by $1 \mathrm{ml}$ of tetramethylammonium hydroxide and then dried in air. Finally the developed MNPs were stored in airtight containers.

\section{Synthesis of SA/PVP-co-VAc/MNPs microbeads}

The magnetite nanoparticles loaded microbeads were prepared using simple ionotropic gelation technique. Exactly a weighed amount of magnetite nanoparticles (table 1) were added to $5 \mathrm{ml}$ of double-distilled water and placed for sonication for $5 \mathrm{~min}$. The resulting solution was gradually added to a blend ratio of SA/PVP-co-VAc (table 1), followed by addition of drug and GA (table 1) and stirred for $3 \mathrm{~h}$.

The resulting solution is placed for sonication for $10 \mathrm{~min}$ to get a homogeneous solution. The resulting homogeneous suspension was added dropwise into $\mathrm{CaCl}_{2}$ solution under constant stirring at room temperature; the spherical beads formed instantly were kept aside for $20 \mathrm{~min}$. The obtained wet beads were collected by decantation, washed with double distilled water to remove the drug attached on the bead surface, and finally were dried in air overnight at room temperature.

Table 1: Formulation and composition of all samples

\begin{tabular}{|c|c|c|c|c|c|}
\hline \multirow[t]{2}{*}{ Formulation code } & \multicolumn{2}{|c|}{ Polymers (\%w/v) } & \multirow[t]{2}{*}{ MNPs (mg) } & \multirow[t]{2}{*}{ Drug (mg) } & \multirow[t]{2}{*}{ GA (ml) } \\
\hline & SA & PVP-co-VAc & & & \\
\hline F1 & 80 & 20 & 20 & 100 & 1 \\
\hline $\mathrm{F} 2$ & 60 & 40 & 20 & 100 & 1 \\
\hline F3 & 40 & 60 & 20 & 100 & 1 \\
\hline $\mathrm{F} 4$ & 80 & 20 & 20 & 150 & 1 \\
\hline F5 & 80 & 20 & 20 & 200 & 1 \\
\hline F6 & 80 & 20 & 20 & 100 & 2.5 \\
\hline F7 & 80 & 20 & 20 & 100 & 5 \\
\hline F8 & 80 & 20 & 00 & 00 & 1 \\
\hline
\end{tabular}

(Results are expressed as mean $\pm \mathrm{SD}, \mathrm{n}=3$ )

\section{Characterization methods}

\section{Fourier transform infrared (FTIR) spectral analysis}

Fourier Transmission infrared spectra of CUR, MNPs, placebo microbeads, and drug loaded microbeads were recorded using FTIR spectrophotometer (model Bomem MB-3000, with Horizon MBTM FTIR software) in the wavelength range of $400-4000 \mathrm{~cm}^{-1}$ to find out the possible chemical interactions between polymers and drug.

\section{Differential scanning calorimetry (DSC)}

DSC curves of CUR, MNPs, placebo microbeads, and drug-loaded microbeads were recorded using thermogravimetric analyzer Rheometric Scientific, Model DSC-SP, UK. The analysis was performed by heating each sample from $40{ }^{\circ} \mathrm{C}$ to $600{ }^{\circ} \mathrm{C}$ at the heating rate of $10^{\circ} \mathrm{C} / \mathrm{min}$ under nitrogen atmosphere.

\section{Thermogravimetric analysis (TGA)}

Thermogravimetric analysis of CUR, MNPs, placebo microbeads, and drug-loaded microbeads were carried out using thermogravimetric analyzer Rheometric Scientific, Model DSC-SP, UK. About 10-12 mg of sample was placed into alumina crucible and the thermograms were recorded between $40{ }^{\circ} \mathrm{C}$ to $600{ }^{\circ} \mathrm{C}$ at a heating rate of 10 ${ }^{\circ} \mathrm{C} / \mathrm{min}$ under nitrogen atmosphere.

\section{X-Ray diffraction (X-RD) analysis}

The X-ray diffraction of CUR, placebo microbeads, drug-loaded microbeads, MNPs and MNPs/drug-loaded microbeads were performed by a wide-angle X-ray scattering diffractometer (Panalytical X-ray Diffractometer, model-X'pert Pro) with $\mathrm{Cu}-\mathrm{K} \alpha$ radiation $(\lambda=1.54060)$ at a scanning rate of $10^{\circ} / \mathrm{min}$ to determine the crystallinity.

\section{Scanning electron microscopy (SEM) analysis}

The morphological characterization of microbeads and MNPs was observed using SEM (JOEL MODEL JSM 840A) with an accelerated voltage of $20 \mathrm{kV}$.

\section{Swelling measurements}

The swelling behavior of different formulations was determined gravimetrically under both $\mathrm{pH} 1.2$ and $\mathrm{pH} 7.4$

\section{Encapsulation efficiency}

The percentage encapsulation efficiency of CUR loaded microbeads was estimated according to the formula and method reported in previous literature [30]. A known mass of drug-loaded microbeads $(20 \mathrm{mg}$ ) was immersed into $100 \mathrm{ml}$ of phosphate buffer solution (pH 7.4 containing $5 \%$ absolute ethyl alcohol) for $24 \mathrm{~h}$ and then vigorously stirred to ensure the complete extraction of CUR from the microbeads. Supernatants were filtered and analyzed by ultraviolet (UV) spectrophotometer (LabIndia, Mumbai, India) at the $\lambda_{\max }$ of 470 $\mathrm{nm}$ with placebo microbeads as blank correction. Concentration of drug was determined using calibration curve constructed by series of CUR standard solutions and the percentage of encapsulation efficiency was determined using the following formula.

$$
\text { Encapsulation efficiency percentage }(\mathrm{EE} \%)=\frac{\mathrm{w}_{\mathrm{t}}}{\mathrm{W}_{\mathrm{i}}} \times 100
$$

Where $W_{t}$ is the total amount of drug in the microspheres and $W_{i}$ is the total quantity of drug added initially during the preparation.

\section{In vitro drug release studies}

In vitro drug release studies for different formulations were performed using a dissolution tester containing eight baskets at $37^{\circ} \mathrm{C}$ in $900 \mathrm{ml}$ of phosphate buffer solution (pH-7.4) at a rotation speed of $50 \mathrm{rpm}$ 
to replicate intestinal atmosphere. The accurately weighed $100 \mathrm{mg}$ of microbeads were used for the study. At regular intervals of time, 5 $\mathrm{ml}$ aliquot samples were withdrawn and analyzed using UV spectrophotometer at fixed $\lambda_{\max }$ value of $470 \mathrm{~nm}$, and the released drug amount was obtained using concentration versus absorbance calibration curve.

\section{RESULTS AND DISCUSSION}

\section{FTIR analysis}

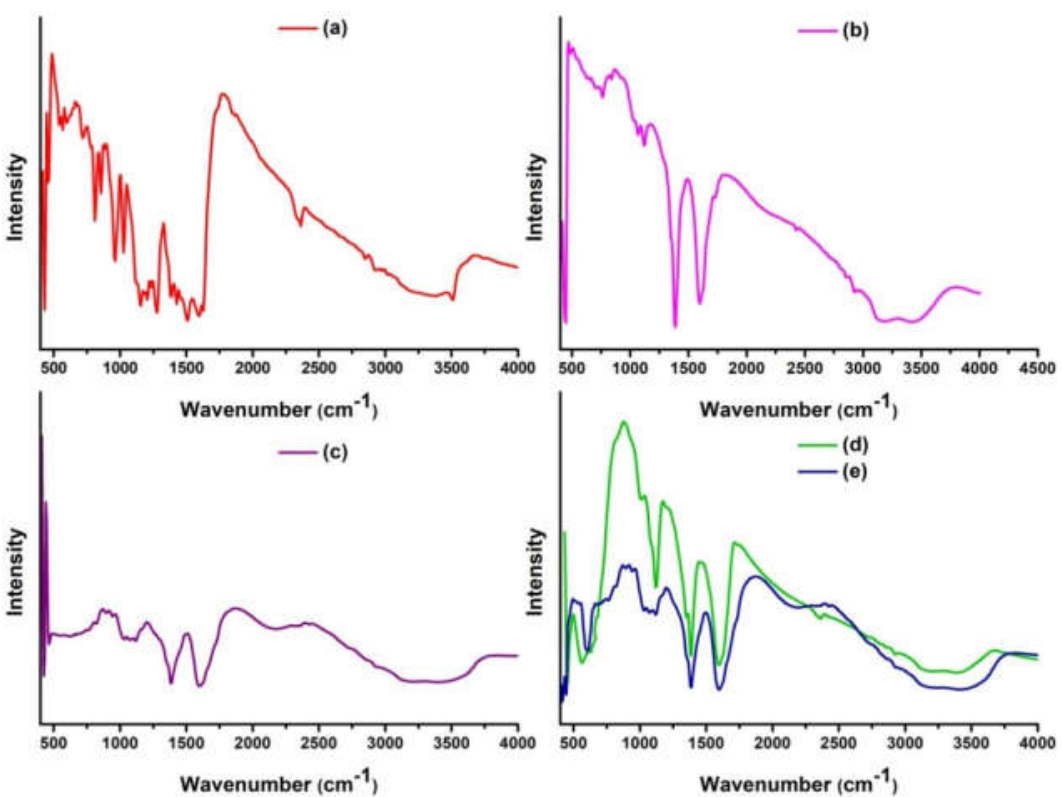

Fig. 1: FTIR spectra of CUR (a), placebo microbeads (b), drug-loaded microbeads (c), MNPs (d) and MNPs-drug-loaded microbeads (e)

The FTIR spectral studies were used to confirm the formation of microbeads. FTIR spectra of CUR (a), placebo microbeads (b), drug loaded microbeads (c), MNPs (d) and drug-loaded MNPs microbeads (e) are shown in fig. 1. FTIR spectra of placebo microbeads (fig. 1b), a peak observed at $3341 \mathrm{~cm}^{-1}$ is responsible for $\mathrm{O}-\mathrm{H}$ stretching frequency, a peak at $1609 \mathrm{~cm}^{-1}$ indicates $\mathrm{C}=0$ stretching frequency. In addition to the above, peaks at $1387 \mathrm{~cm}^{-1}$ and $1121 \mathrm{~cm}^{-1}$ corresponds to $\mathrm{C}-\mathrm{N}$ stretching and bending vibrations. The FTIR spectra of CUR (fig. 1a), shows a broad peak at $3493 \mathrm{~cm}^{-1}$ assigned to $\mathrm{O}-\mathrm{H}$ stretching frequency of phenolic group. The peak at $2923 \mathrm{~cm}^{-1}$ corresponds to C-H stretching vibrations, the peaks at 1596 and $1513 \mathrm{~cm}^{-1}$ were assigned to stretching vibration of benzene ring skeleton and mixed $(\mathrm{C}=0)$ and $(\mathrm{C}=\mathrm{C})$ vibration respectively. The band at $1272 \mathrm{~cm}^{-1}$ corresponds to Ar-O stretching vibrations [33] On comparing the drug-loaded microbeads (fig. 1c) with placebo microbeads (fig. 1b) a new peak was observed in the drug-loaded microbeads at $1029 \mathrm{~cm}^{-1}$ and also a broad peak appeared at 1601 $\mathrm{cm}^{-1}$ due to the carbonyl group of CUR, which confirmed that the drug molecules are successfully encapsulated in the microbeads. The FTIR spectra of MNPs (fig. 1d) show a peak at $565 \mathrm{~cm}^{-1}$ due to Fe-O stretching frequency, peaks at $1598 \mathrm{~cm}^{-1}$ and $3421 \mathrm{~cm}^{-1}$ are due to bending and stretching vibrations of $\mathrm{O}-\mathrm{H}$ group which are attached to iron atoms on the surface [34]. In the case of MNPs-drug-loaded microbeads (fig. 1e), similar to drug-loaded microbeads all peaks were observed in MNPs-drug-loaded microbeads, along with a new peak observed at $611 \mathrm{~cm}^{-1}$ due to the presence of $\mathrm{Fe}-\mathrm{O}$ group, which confirms that the MNPs are successfully loaded in the microbeads.

\section{DSC analysis}

Typical DSC thermograms of CUR (a), placebo microbeads (b), drugloaded microbeads (c), MNPs-drug-loaded microbeads (d) and MNPs (e) are depicted in fig. 2.

The DSC curve of placebo microbeads (fig. 2b) show two endothermic peaks at 87 and $205^{\circ} \mathrm{C}$. The DSC curve of CUR (fig. 2a) shows a endothermic peak at $181{ }^{\circ} \mathrm{C}$ due to its melting, whereas no such peak was observed in drug-loaded microbeads (fig. 2c), which confirms that the drug has been molecularly dispersed in the microbeads. DSC curve of MNPs (fig. 2e) show an exothermic peak at $572{ }^{\circ} \mathrm{C}$ due to phase transition from $\gamma-\mathrm{Fe}_{2} \mathrm{O}_{3}$ to $\alpha-\mathrm{Fe}_{2} \mathrm{O}_{3}$, whereas no such peak was observed in MNPs-drug-loaded microbeads (fig. $2 \mathrm{~d}$ ), which indicates the stability of MNPs-drug-loaded microbeads due to the interaction between $\gamma-\mathrm{Fe}_{2} \mathrm{O}_{3}$ and polymer matrix [35].

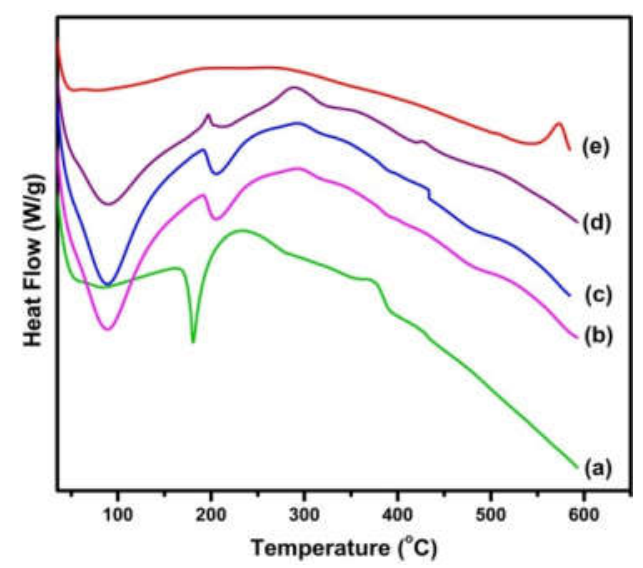

Fig. 2: DSC curves of CUR (a), placebo microbeads (b), drug loaded microbeads (c), MNPs-drug loaded microbeads (d) and MNPs (e)

\section{TGA analysis}

TGA thermograms of CUR (a), placebo microbeads (b), drug-loaded microbeads (c), MNPs-drug-loaded microbeads (d) and MNPs (e) are 
displayed in fig. 3. The TGA curve of CUR (fig. 3a) showed a weight loss between the ranges of $50-204{ }^{\circ} \mathrm{C}$ due to loss of residual water, followed by a weight loss at $210-398^{\circ} \mathrm{C}$ due to the decomposition of CUR. The TGA curve of placebo microbeads (fig. 3b) shows three weight loss steps. The first step was observed in the region of 50 $193{ }^{\circ} \mathrm{C}$ with weight loss of $23 \%$ due to evaporation of water physically adsorbed on the polymer matrix. The second weight-loss step was observed in the range of $197-313^{\circ} \mathrm{C}$ with weight loss of 26 $\%$ due to the decomposition of polymer matrix and the last step with weight loss of $19 \%$ in the region of $317-600{ }^{\circ} \mathrm{C}$ due to the complete decomposition of polymer matrix. The TGA curve of drug-loaded microbeads (fig. 3c) also shows three consecutive weight loss steps. The first weight loss of $22 \%$ was found in the region of $50-190{ }^{\circ} \mathrm{C}$ and is attributed to the loss of water bounded on the surface of polymer matrix. The second and third steps were observed in the range of $195-305^{\circ} \mathrm{C}$ and $309-600^{\circ} \mathrm{C}$ with a weight loss of 30 and 20 $\%$ respectively due to the decomposition of the polymer matrix. TGA curve of MNPs (fig. 3e) shows a weight loss of $7 \%$ over the range of 50-600 ${ }^{\circ} \mathrm{C}$ indicating that no significant weight loss took place. In the case of MNPs-drug loaded microbeads (fig. 3d), TGA curves show three weight loss steps. The first weight loss step was observed over the range of $50-191{ }^{\circ} \mathrm{C}$ with weight loss of $34 \%$ due to the loss of free and bound water from the polymer matrix. The second and third weight loss steps was found in the region of $197-301{ }^{\circ} \mathrm{C}$ and $305-600{ }^{\circ} \mathrm{C}$, with weight loss of 20 and $16 \%$ due to the decomposition of polymer matrix. From the TGA results, it is suggested that the drug-loaded microbeads and MNPs-drug-loaded microbeads show an overall improvement in the thermal stability of microbeads.

\section{SEM analysis}

The topographical images of microbeads and MNPs are investigated by SEM analysis and the images are displayed in fig. 4. The SEM images of microbeads (fig. $4 \mathrm{a}$ and $4 \mathrm{~b}$ recorded at 85 and 330 resolutions respectively) reveal that they have a rough surface with porous nature. The average diameter of the microbeads obtained from the SEM was in the range of 1080 to $1030 \mu \mathrm{m}$. The fig. $4 \mathrm{c}$ and $4 \mathrm{~d}$ recorded at 25,000 resolution reveals that the synthesized magnetite particles are in the range of nanometers. This confirmed that the developed magnetite particles are MNPs. Further it was confirmed by X-RD, DSC and TGA analysis.

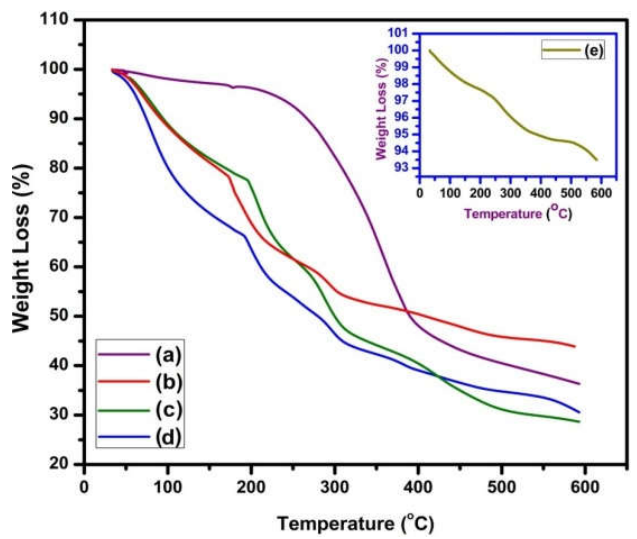

Fig. 3: TGA curves of CUR (a), placebo microbeads (b), drug loaded microbeads (c), MNPs-drug-loaded microbeads (d) and MNPs (e)

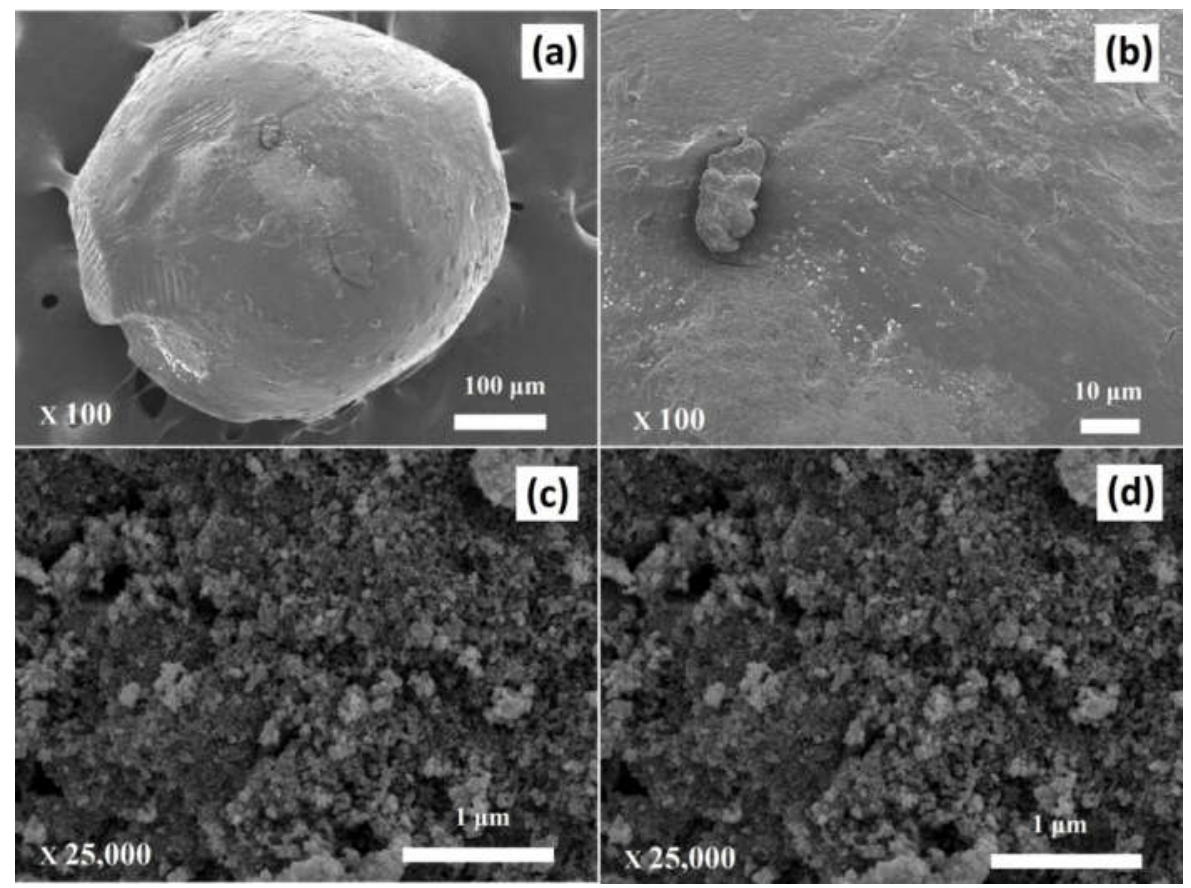

Fig. 4: SEM analysis of drug and MNPs loaded microspheres (a, b), synthesized magnetic nanoparticles (c, d)

\section{X-RD analysis}

X-RD patterns of CUR (a), MNPs (b), placebo microbeads (c), drug-loaded microbeads (d) and MNPsdrug-loaded microbeads (e) are displayed in fig. 5. The X-RD pattern of MNPs (fig. $5 \mathrm{~b}$ ) show a peak at $35.70^{\circ}$ due to

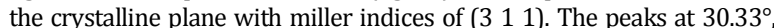
$43.44^{\circ}, 54.23^{\circ}, 57.31^{\circ}$ and $62.91^{\circ}$ match the magnetite diffraction pattern reported by Banerjee et al., [36]. The results suggest that the developed
MNPs were $\mathrm{Fe}_{3} \mathrm{O}_{4}$ nanoparticles. The X-RD pattern of CUR (fig. $5 \mathrm{a}$ ) shows the most intensive peaks in the $2 \theta$ region of $12-28^{\circ}$, suggesting its crystalline nature. Whereas these peaks have not appeared in drugloaded microbeads (fig. 5d), suggesting that the drug has been molecularly dispersed in the polymer matrix. X-RD pattern of MNPsdrug-loaded microbeads (fig. 5e) show peaks similar to that of MNPs at $30.21^{\circ}, 35.89^{\circ}, 57.51^{\circ}$ and $62.97^{\circ}$ indicating that the MNPs are successfully loaded in the microbeads. 

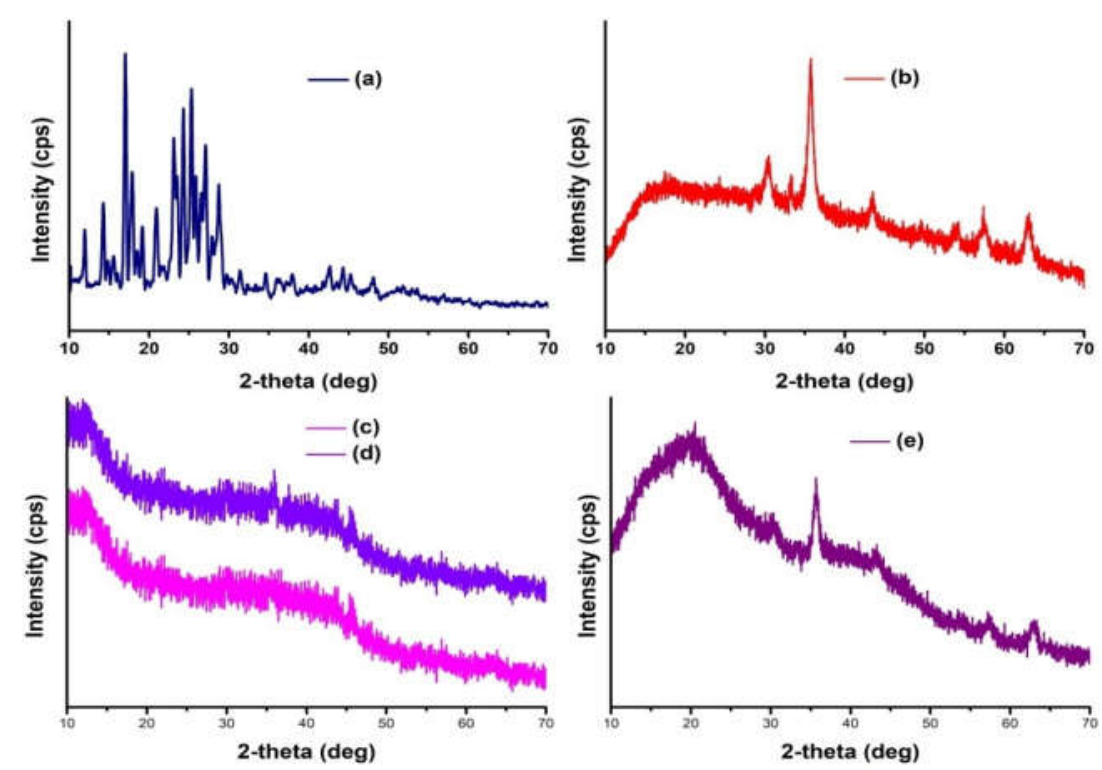

Fig. 5: X-RD patterns of CUR (a), MNPs (b), placebo microbeads (c), drug loaded microbeads (d) and MNPs-drug loaded microbeads (e)

\section{Encapsulation efficiency}

The percentage encapsulation efficiency of developed CUR encapsulated microbeads was found to be between $39 \%$ and $50 \%$ (table 2). Three different concentrations of CUR, i.e., 100, 150, and $200 \mathrm{mg}$ were encapsulated with constant amounts of MNPs and GA. As the \% of drug loading is increased, \% EE also increased from 45 to $48 \%$; this trend may be due to higher drug concentration, which causes entrapment of more number of drug molecules in the polymeric matrix leading to higher \%EE. With increasing crosslinker concentration, \% EE decreased. For instance, with an increase of GA from 1 to $5 \mathrm{ml}, \%$ EE decreased from 45 to $39 \%$. Such a decrease in trend could be attributed to decrease in free volume spaces in the polymeric matrix due to increased crosslinking density, thereby reducing encapsulation efficiency. Further with increasing the $\%$ of PVP-co-VAc from 20 to $60 \%$ (The SA percentage decreased from 80 to $40 \%$ ) the $\%$ EE increased from 45 to 50 , this may be due to more interactions between hydrophobic groups of CUR and PVP-co-VAc, whereas in SA the presence of ionic COO-groups inhibited such interactions.

Table 2: Encapsulation efficiency (\% EE) of all samples, (Results are expressed as mean \pm SD, $n=3$ )

\begin{tabular}{lll}
\hline S. No. & Formulation code & \% EE \\
\hline 1 & F1 & $45 \pm 1.3$ \\
2 & F2 & $47 \pm 0.8$ \\
3 & F3 & $50 \pm 1.4$ \\
4 & F4 & $46 \pm 1.1$ \\
5 & F5 & $48 \pm 1.5$ \\
6 & F6 & $42 \pm 1.3$ \\
7 & F7 & $39 \pm 0.6$ \\
\hline
\end{tabular}

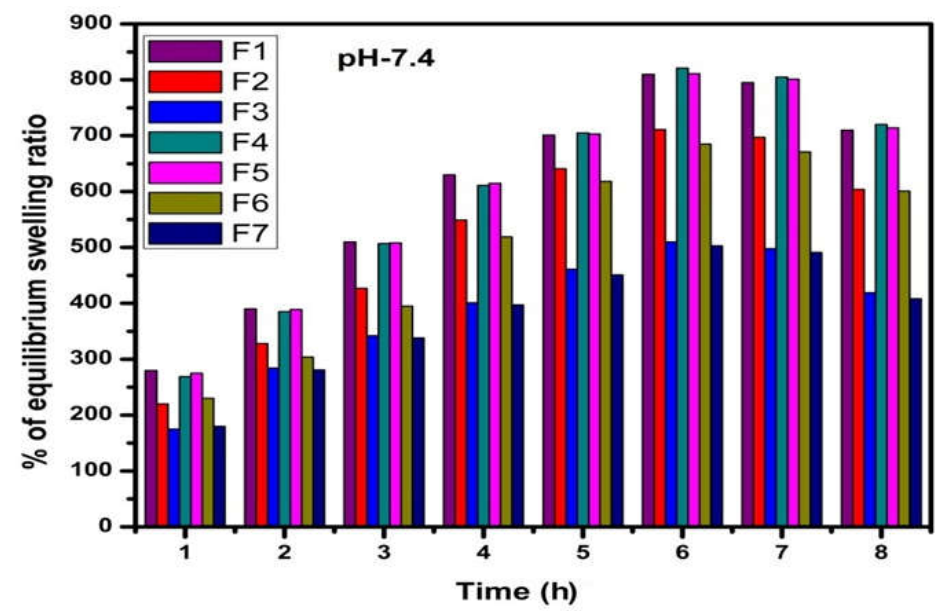

Fig. 6a: Equilibrium swelling ratio for all profiles at $\mathrm{pH} 7.4,($ Results are expressed as mean $\pm \mathrm{SD}, \mathrm{n}=3$ ) 


\section{Swelling studies}

Swelling properties play a crucial role in biomedical applications such as diffusion of drugs, nutrients and other water-soluble metabolites and also for controlled release in drug delivery systems. In order to find out the suitability of microbeads for gastrointestinal drug delivery, swelling studies were performed under both $\mathrm{pH} 7.4$ (simulated intestinal fluid) and 1.2 (simulated gastric fluid) at $37{ }^{\circ} \mathrm{C}$ and the results are displayed in fig. $6 \mathrm{a}$ and $6 \mathrm{~b}$, respectively. The swelling results indicate that the swelling degree is high in the case of $\mathrm{pH} 7.4$ rather than in the case of $\mathrm{pH}$ 1.2. This is because, in lower $\mathrm{pH}$ (1.2),- $\mathrm{COOH}$ groups of polymer molecule forms a hydrogen bonding with the solvent molecules, which results in the shrinking of polymer network consequently swelling degree decreases. Whereas at higher $\mathrm{pH}$ (7.4) the ionic-COO-groups of polymer molecules repel the water molecules due to the existence of ionic repulsions. Therefore there is no chance for the formation of hydrogen bonding, which ultimately increases the swelling degree at higher $\mathrm{pH}$ (7.4) conditions [37].

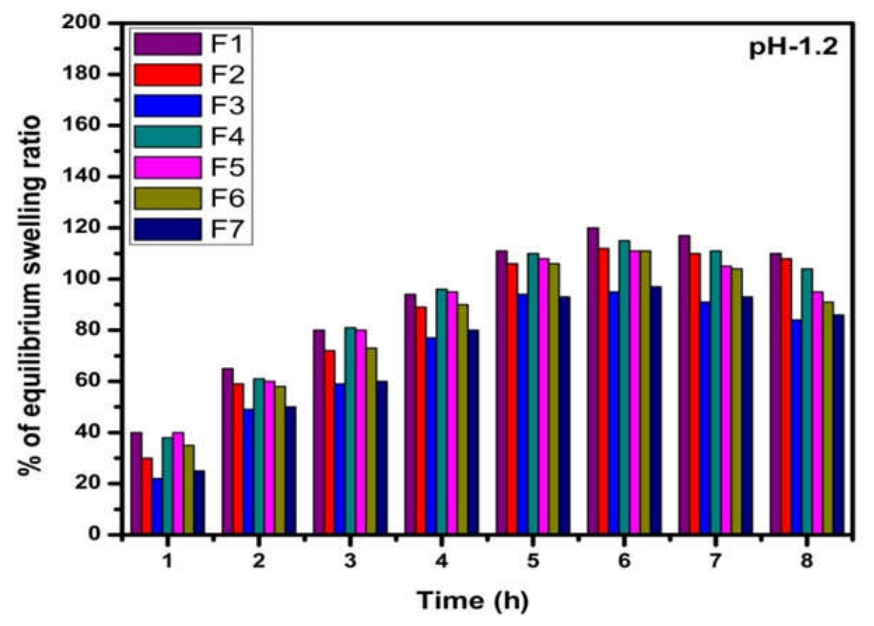

Fig. 6b: Equilibrium swelling ratio for all profiles at pH 1.2, (Results are expressed as mean $\pm S D, n=3$ )

\section{In vitro studies}

The in vitro drug release studies of microbeads under study are investigated under both $\mathrm{pH} 1.2$ and $\mathrm{pH} 7.4$ at $37^{\circ} \mathrm{C}$. The cumulative $\%$ of drug release for all profiles at $\mathrm{pH} 1.2$ are displayed in fig. 7 . The in vitro release studies for all profiles at $\mathrm{pH} 7.4$ are discussed in terms of polymer blend composition (fig. 8), drug loading (fig. 9) and crosslinker variation (fig. 10). The results reveal that the release rate is higher at $\mathrm{pH} 7.4$ rather than at $\mathrm{pH} 1.2$, this is because at $\mathrm{pH} 7.4$ the carboxylate groups have less interactions with buffer medium, therefore, the network becomes more slack; hence, the entrapped drug molecules easily leach out from the network when compared to $\mathrm{pH} 1.2$.

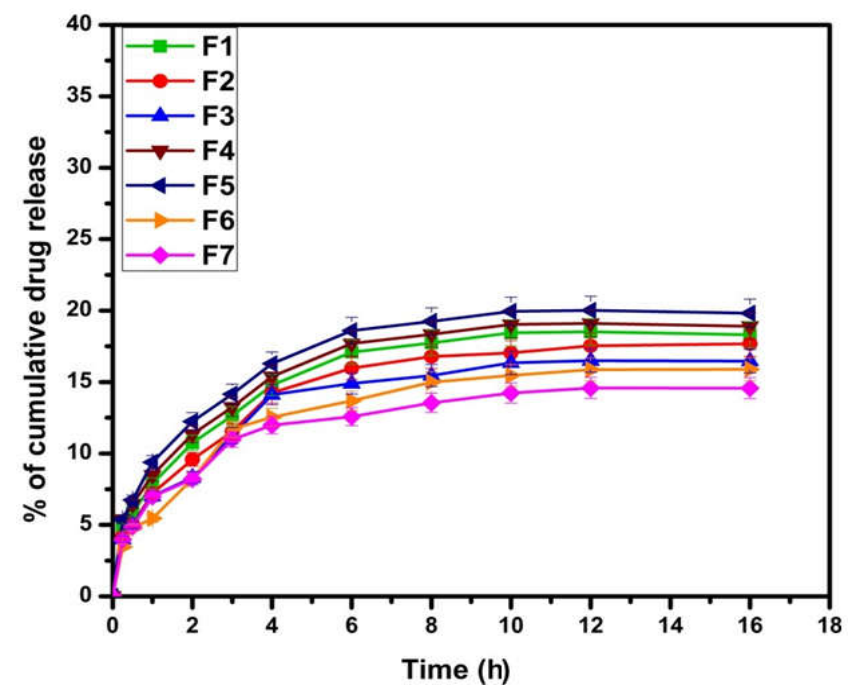

Fig. 7: Cumulative \% of drug release in pH 1.2 at $37^{\circ} \mathrm{C}$, (Results are expressed as mean $\left.\pm S D, n=3\right)$

\section{Polymer variation}

Cumulative \% of drug release was influenced by changing the polymer blend ratio at constant drug content (100 $\mathrm{mg})$ and crosslinker content $(1 \mathrm{ml})$. From the fig. 8 it was clearly observed that as the content of PVP-co-VAc increased, the cumulative $\%$ of drug release decreased. This trend is observed in the formulations of F1 (80:20), F2 (60:40) and F3 (40:60).

This is due to the presence of hydrophobic part (vinyl acetate) in the polymer matrix, consequently decreasing the leaching of an entrapped drug from the polymer matrix in to the buffer media. 


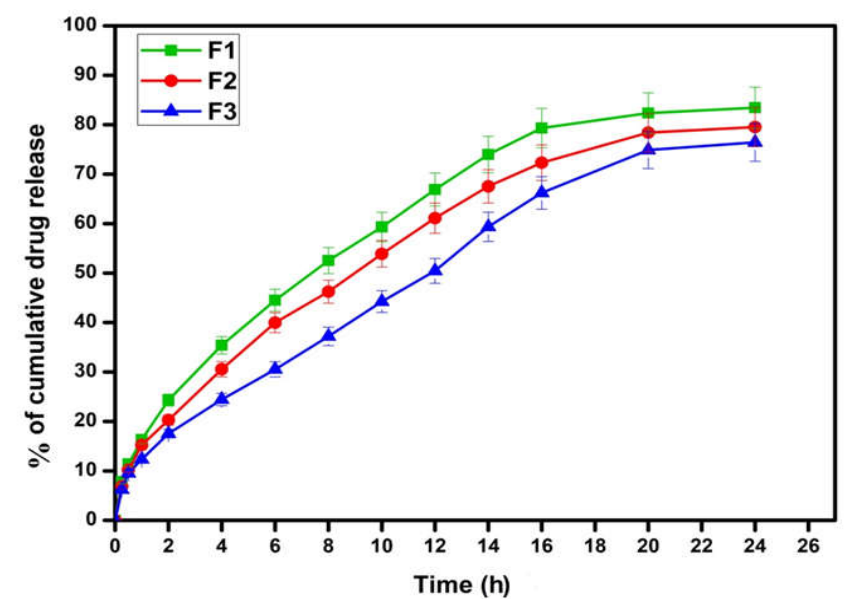

Fig. 8: Effect of polymer blend composition on \% cumulative drug release in $\mathrm{pH} 7.4$ at $37^{\circ} \mathrm{C}($ Results are expressed as mean $\pm \mathrm{SD}, \mathrm{n}=3$ )

\section{Drug variation}

The effect of drug content on cumulative \% of drug release rate was observed by varying the drug content at constant polymer blend ratio $(80: 20)$ and crosslinker content $(1 \mathrm{ml})$. The effect of drug content was observed in the formulations F1 (100 mg), F4 (150 mg) and F5 (200 mg) and the results are displayed in fig. 9. The formulation F5 shows a higher release rate than the F4 and F1; thus it was concluded that the release depends on the drug present in the matrices i.e., higher the drug, higher is the drug release rate and vice-versa. In other words, lower the amount of drug, lower the drug release rate was observed due to the availability of more free void spaces through which a lesser number of drug molecules could be transported [38].

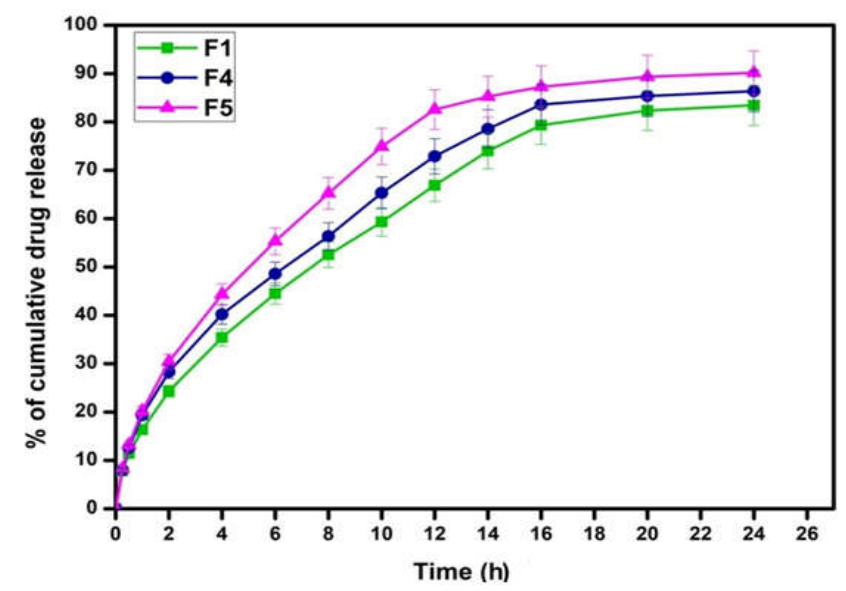

Fig. 9: Effect of drug content on cumulative $\%$ of drug release in $\mathrm{pH} 7.4$ at $37^{\circ} \mathrm{C}($ Results are expressed as mean $\pm \mathrm{SD}, \mathrm{n}=3$ )

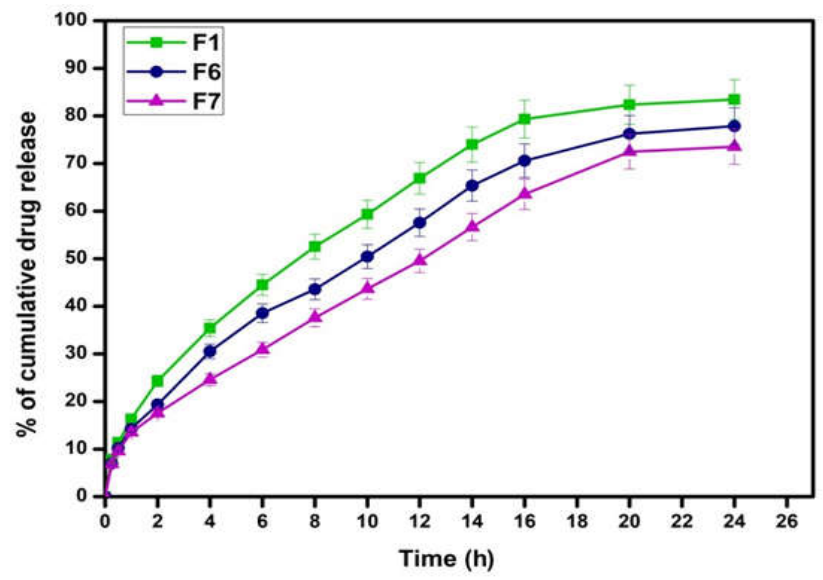

Fig. 10: Effect of crosslinker content on cumulative \% of drug release in $\mathrm{pH} 7.4$ at $37^{\circ} \mathrm{C}($ Results are expressed as mean $\pm \mathrm{SD}$, $\mathrm{n}=3$ ) 
Table 3: Results of \% of release kinetics parameters ( $k$ and $n$ ) of drug in different IPN microbeads formulations

\begin{tabular}{lll}
\hline Sample & Korsmeyer-peppas & \\
\cline { 2 - 3 } & $\mathbf{n}$ & $\mathbf{r}^{2}$ \\
\hline F1 & 0.526 & 0.998 \\
F2 & 0.530 & 0.998 \\
F3 & 0.506 & 0.995 \\
F4 & 0.540 & 0.994 \\
F5 & 0.562 & 0.996 \\
F6 & 0.552 & 0.997 \\
F7 & 0.493 & 0.997 \\
\hline
\end{tabular}

\section{Crosslinker variation}

The effect of crosslinker on the $\%$ of drug release rate for formulations F1, F6 and F7 are investigated and the results are displayed in fig. 10 . It was clearly noticed that the $\%$ of drug release rate of F1 (GA-1 ml) is higher than the F6 (GA-2.5 ml) and F7 (GA-5 $\mathrm{ml}$ ), because as the crosslinker content increases the \% of drug release rate decreases. As the crosslinker content increases, the polymer network becomes more rigid; hence the drug molecules have less chance to escape from the polymer matrix; therefore, the drug release rate decreases [39].

\section{Drug release kinetics}

To confirm the release mechanism, the in vitro release results were fitted to the following Korsmeyer-Peppas equation.

$$
\mathrm{M}_{\mathrm{t}} / \mathrm{M}_{\alpha}=\mathrm{kt}^{\mathrm{n}}
$$

Where $M_{t} / M_{\alpha}$ represents the fractional drug release at time $t, k$ is a constant characteristic of the drug-polymer system and $n$ is the release exponent indicating the type of drug release mechanism. In the present study, the values ' $n$ ' are obtained in the range of 0.493-0.562, leading to a shift of transport from Fickian to anomalous type. These results, along with correlation coefficients, $\mathrm{r}^{2}$ are presented in table 3 .

\section{CONCLUSION}

In the present study, SA/PVP-co-VAc/MNPs microbeads were fabricated by a simple ionotropic gelation technique. The microbeads were confirmed by FTIR and DSC studies. Chemical stability and molecular level dispersion of CUR in microbeads were confirmed by FTIR, DSC, TGA, and X-RD, respectively. SEM studies reveal that the beads were spherical in shape with a rough surface and the average diameter of microbeads was found to be 1080 to $1030 \mu \mathrm{m}$. The swelling and in vitro release studies performed at both $\mathrm{pH} 1.2$ and 7.4 reveal that at $\mathrm{pH} 7.4$ highest swelling and release was observed. In vitro releases studies were fitted into the KorsmeyerPeppas equation, leading to a shift of transport from Fickian to anomalous type. Since the therapeutic efficacy of CUR and MNPs are established previously, based on the drug release studies of CUR loaded SA/PVP-co-VAc/MNPs microbeads, it is observed that the combination of MNPs has not effected the drug release kinetics of CUR. Hence it is suggested that the developed SA/PVP-co-VAc/MNP microbeads were potentially good carriers for drug delivery of CUR and augment chemotherapeutic procedures.

\section{ACKNOWLEDGEMENT}

The authors MCS Subha and K Chowdoji Rao acknowledge the financial support provided by UGC in the form of UGC-BSR faculty fellowship.

\section{AUTHORS CONTRIBUTIONS}

All the author have contributed equally.

\section{CONFLICT OF INTERESTS}

The author(s) declared no potential conflicts of interest with respect to the research, authorship, and/or publication of this article.

\section{REFERENCES}

1. Nokhodchi A, Raja S, Patel P, Asare Addo K. The role of ora controlled release matrix tablets in drug delivery systems. BioImpacts: BI 2012;2:175-87.
2. Ișılan N, İnal M, Yigitoglu M. Synthesis and characterization of poly(N-vinyl-2-pyrrolidone) grafted sodium alginate hydrogel beads for the controlled release of indomethacin. J Appl Polym Sci 2008;110:481-93.

3. Pandey SP, Shukla T, Dhote VK, K Mishra D, Maheshwari R, Tekade RK. Chapter 4-use of polymers in controlled release of active agents. In: Tekade RK. (editor). Basic fundamental of drug delivery: Academic Press; 2019. p. 113-72.

4. Reddy OS, Subha MCS, Jithendra T, Madhavi C, Chowdoji Rao K. Fabrication of Gelatin/Karaya gum blend microspheres for the controlled release of distigmine bromide. J Drug Delivery Ther 2019;9:1-11.

5. Al-Kahtani AA, Sherigara BS. Semi-interpenetrating network of acrylamide-grafted-sodium alginate microspheres for controlled release of diclofenac sodium, preparation and characterization. Colloids Surf B Biointerfaces 2014;115:132-8.

6. Krishna Rao KSV, Kiran Kumar ABV, Madhusudhan Rao K, Subha MCS, Lee YI. Semi-IPN hydrogels based on Poly(vinyl alcohol) for controlled release studies of chemotherapeutic agentand their swelling characteristics. Polym Bull 2008;61:81-90.

7. Reddy OS, Subha MCS, Jithendra T, Madhavi C, Rao KC, Mallikarjuna B. Sodium alginate/gelatin microbeadsintercalated with kaolin nanoclay for emerging drug delivery in wilson's disease. Int J Appl Pharm 2019;11:71-80.

8. Reddy OS, Subha MCS, Jithendra T, Madhavi C, Rao KC. Fabrication and characterization of smart karaya gum/sodium alginate semi-IPN microbeads for controlled release of Dpenicillamine drug. Polym Polym Compos 2020;29:1-13.

9. Samanta HS, Ray SK. Synthesis, characterization, swelling and drug release behavior of semi-interpenetrating network hydrogels of sodium alginate and polyacrylamide. Carbohydr Polym 2014;99:666-78.

10. Shi G, Ding Y, Zhang X, Wu L, He F, Ni C. Drug release behavior of poly (lactic-glycolic acid) grafting from sodium alginate (ALG-g-PLGA) prepared by direct polycondensation. J Biomater Sci Polymer Edition 2015;26:1152-62.

11. Pina MF, Zhao M, Pinto JF, Sousa JJ, Craig DQM. The influence of physical drug state on the dissolution enhancement of solid dispersions prepared via hot-melt extrusion: a case study using olanzapine. J Pharm Sci 2014;103:1214-23.

12. Bailly N, Thomas M, Klumperman B. Poly(N-vinylpyrrolidone)block-poly(vinyl acetate) as a drug delivery vehicle for hydrophobic drugs. Biomacromolecules 2012;13:4109-17.

13. Savita B, Anirban M. Systemic delivery of curcumin: 21st century solutions for an ancient conundrum. Curr Drug Discovery Technol 2009;6:192-9.

14. Srimal RC, Dhawan BN. Pharmacology of diferuloylmethane (curcumin), a non-steroidal anti-inflammatory agent. J Pharm Pharmacol 1973;25:447-52.

15. Kumar A, Singh M, Singh PP, Singh SK, Raj P, Pandey KD. Antioxidant efficacy and curcumin content of turmeric (Curcuma-Longa L.) flower. Int J Curr Pharm Res 2016;8:112-4.

16. Kim MK, Choi GJ, Lee HS. Fungicidal property of Curcuma longa L. rhizome-derived curcumin against phytopathogenic fungi in a greenhouse. J Agric Food Chem 2003;51:1578-81.

17. Deodhar Sd Fau-Sethi R, Sethi R Fau-Srimal RC, Srimal RC. Preliminary study on antirheumatic activity of curcumin (diferuloylmethane). Indian J Med Res 1980;71:632-4.

18. Reddy OS, Subha MCS, Jithendra T, Madhavi C, Chowdoji Rao K. Emerging novel drug delivery system for control release of curcumin through sodium alginate/poly(ethylene glycol) semi 
IPN microbeads-intercalated with kaolin nanoclay. J Drug Delivery Ther 2019;9:324-33.

19. Lachowicz D, Karabasz A, Bzowska M, Szuwarzynski M, Karewicz A, Nowakowska M. Blood-compatible, stable micelles of sodium alginate-Curcumin bioconjugate for anti-cancer applications. Eur Polym J 2019;113:208-19.

20. Lu AH, Salabas EL, Schüth F. Magnetic nanoparticles: synthesis, protection, functionalization, and application. Angew Chem Int Ed 2007;46:1222-44.

21. Ito A, Shinkai M, Honda H, Kobayashi T. Medical application of functionalized magnetic nanoparticles. J Biosci Bioeng 2005;100:1-11.

22. Saiyed ZM, Telang SD, Ramchand CN. Application of magnetic techniques in the field of drug discovery and biomedicine Biomagn Res Technol 2003;1:1-8.

23. Namdeo M, Saxena S Fau Tankhiwale R, Tankhiwale R Fau Bajpai M, Bajpai M Fau Mohan YM, Mohan Ym Fau Bajpai SK, Bajpai SK. Magnetic nanoparticles for drug delivery applications. J Nanosci Nanotechnol 2008;8:3247-71.

24. Cole AJ, Yang VC, David AE. Cancer theranostics: the rise of targeted magnetic nanoparticles. Trends Biotechnol 2011;29:323-32.

25. Maeda H. Tumor-selective delivery of macromolecular drugs via the EPR effect: background and future prospects. Bioconjug Chem 2010;21:797-802.

26. Pollert E, Veverka P, Veverka M, Kaman O, Zaveta K, Vasseur S, et al. Search of new core materials for magnetic fluid hyperthermia: preliminary chemical and physical issues. Progress Solid State Chem 2009;37:1-14.

27. Veiseh O, Gunn JW, Zhang M. Design and fabrication of magnetic nanoparticles for targeted drug delivery and imaging. Adv Drug Delivery Rev 2010;62:284-304.

28. Zhang L, Yu F, Cole AJ, Chertok B, David AE, Wang J, et al. Gum arabic-coated magnetic nanoparticles for potential application in simultaneous magnetic targeting and tumor imaging. AAPS J 2009;11:693-9.

29. Johannsen M, Gneveckow U, Eckelt L, Feussner A, Waldofner $\mathrm{N}$, Scholz R, et al. Clinical hyperthermia of prostate cancer using magnetic nanoparticles: presentation of a new interstitial technique. Int J Hyperthermia 2005;21:637-47.

30. Wilhelm C, Fortin JP Fau-Gazeau F, Gazeau F. Tumour cell toxicity of intracellular hyperthermia mediated by magnetic nanoparticles. J Nanosci Nanotechnol 2007;7:2933-7.

31. Sun C, Lee JSH, Zhang M. Magnetic nanoparticles in MR imaging and drug delivery. Adv Drug Delivery Rev 2008;60:1252-65.

32. Rajput S, Pittman CU, Mohan D. Magnetic magnetite $\left(\mathrm{Fe}_{3} \mathrm{O}_{4}\right)$ nanoparticle synthesis and applications for lead $\left(\mathrm{Pb}^{2+}\right)$ and chromium $\left(\mathrm{Cr}^{6+}\right)$ removal from water. J Colloid Interface Sci 2016;468:334-46.

33. Madhusudana Rao K, Krishna Rao KSV, Ramanjaneyulu G, Ha CS. Curcumin encapsulated $\mathrm{pH}$ sensitive gelatin-based interpenetrating polymeric network nanogels for anti-cancer drug delivery. Int J Pharm 2015;478:788-95.

34. Lori N, Eydokia P, Vassilis Z, Anna P, Eleana H, Christos NP Magnetic nanoparticles in medical diagnostic applications: synthesis, characterization and proteins conjugation. Curr Nanosci 2016;12:455-68.

35. Zhu HY, Jiang R, Xiao L, Li W. A novel magnetically separable $\gamma$ $\mathrm{Fe}_{2} \mathrm{O}_{3}$ /crosslinked chitosan adsorbent: preparation, characterization and adsorption application for removal of hazardous azo dye. J Hazard Mater 2010;179:251-7.

36. Banerjee SS, Chen DH. Fast removal of copper ions by gum arabic modified magnetic nano-adsorbent. J Hazard Mater 2007;147:792-9.

37. Eswaramma S, Rao KSVK. Synthesis of dual responsive carbohydrate polymer-based IPN microbeads for controlled release of anti-HIV drug. Carbohydr Polym 2017;156:125-34.

38. Madhusudana Rao K, Mallikarjuna B, Krishna Rao KSV, Prabhakar MN, Chowdoji Rao K, Subha MCS. Preparation and characterization of $\mathrm{pH}$ sensitive poly(vinyl alcohol)/sodium carboxymethyl cellulose IPN microspheres for in vitro release studies of an anti-cancer drug. Polym Bull 2012;68:1905-19.

39. Madhavi C, Babu PK, Maruthi Y, Parandhama A, Reddy OS, Rao $\mathrm{KC}$, et al. Sodium alginate-locust bean gum IPN hydrogel beads for the controlled delivery of the nimesulide-anti-inflammatory drug. Int J Pharm 2017;9:245-52. 